\section{SHOP ONLINE FOR CONVENIENCE}

Waymade Healthcare Plc, one of the UK's largest suppliers to retail pharmacy, is launching into dentistry. Click Dental (www.clickdental.com) is the new dental division of Waymade Healthcare Plc and will allow you to shop online for products with the same ease as doing your weekly online food shop.

The site is simple to navigate and fast, so managing your account is easy and will offer you additional benefits including alternative choices that you might like to consider as well as peer assessments of a particular product.

There is no complicated registration process and payment can be made via invoice or via direct debit from your account. There is no minimum order and by using Click Dental's online facility you will be able to control purchasing matters. You can identify product usage which will allow you to exercise greater budgetary management and monitor practice expenses.

Reader response number 54

\title{
WELCOMING SURGERY ENVIRONMENT
}

With a product range benefiting from the latest materials and technology, Tavom offers ergonomic, cost effective and durable solutions to every furnishing dilemma. Stylish contemporary designs, customised or off the shelf, feature throughout the range to comple-

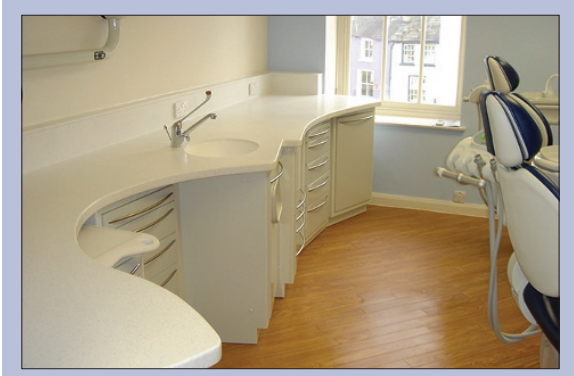

ment any existing floor plans and décor and deliver an environment which is both comfortable and practical.

To meet patients' rising expectations of the dental experience, as well as to attract and retain quality staff, the surgery environment must be welcoming as well as functional. Tavom has trained consultants able to offer advice on the emotional impact of colour compatibility and product suitability for specific purposes. In areas of the practice where heavy use places a premium on durability, functionality and value are guaranteed.

Reader response number 55

\section{ELIMINATE CROSS INFECTION}

Cleankeys Clinical Keyboards, from dental electronics company Micro Minder, provide a solution to bacterial contamination on computer keyboards and mice.

Both visually and functionally more professional, Clinical Keyboards stop the need for wrapping cling film around the keyboard. They offer touch sensitive typing, a built-in mouse trackpad, USB connection, a lock/suspend operation, LED indicators and audible feedback. After one wipe of a disinfecting wipe, Clinical Keyboards are less infected than silicon rubber and regular plastic keyboards.

Reader response number 56

\section{OPTIMUM INFECTION CONTROL}

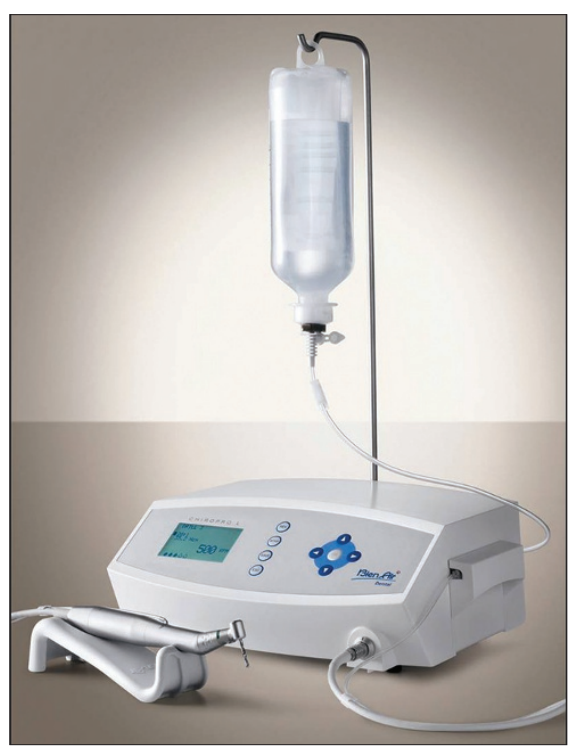

The Bien-Air Chiropro L is a versatile implantology system that has been designed with efficiency and comfort in mind. The intuitive interface can be managed by the control pedal, and the patented peristaltic pump with disposable irrigation lines and insertion support ensures easy handling and optimum infection control.

The Chiropro L system includes the MX-LED self-ventilating motor, which offers LED lighting at equal intensity at both high and low speeds. Incorporating seven of the leading brands of implants with their complete sequences, the Chiropro L can also be customised to your individual requirements.

Featuring an internal irrigation system, the 20:1 contra-angle handpiece incorporates a small head allowing access to the tightest of areas. Fitted with an exclusive double optical glass rod system, the handpiece provides uniform lighting of the operative field.

Reader response number 57

\section{RELIEVE PEAK-TIME MORNING RUSH}

Denticom is a managed service, tailor made for your own practice's environment, that improves both patient access and patient experience. Denticom displays the patient's name and details on screen when the telephone rings allowing a personal welcome.

The system is designed to relieve the chaotic peak-time morning rush and its Perfect Partner allows patients to book, cancel or change appointments any time of day or night over the telephone, integrating seamlessly with the practice's electronic appointment book.

Denticom allows for messages to be played while the patient is on hold, promoting services while letting the patient know their position in the queue and eliminates the engaged tone, improving access.

In the practice, Denticom's Patient Point offers a self check-in service for appointments, a touch-sensitive screen displaying practice specific information such as opening times and services.

Reader response number 58 